\title{
CRESCIMENTO DO MARACUJAZEIRO-DOCE PROPAGADO POR SEMENTES EM FUNÇÃO DA CALAGEM ${ }^{1}$
}

\author{
ELDA BONILHA ASSIS FONSECA ${ }^{2}$ \\ MOACIR PASQUAL ${ }^{3}$ \\ JANICE GUEDES DE CARVALHO \\ JOÃO BATISTA DONIZETI CORRÊA ${ }^{5}$
}

\begin{abstract}
RESUMO - Objetivou-se avaliar as respostas em crescimento do maracujazeiro-doce (Passiflora alata Dryand.) propagado por sementes, quando cultivado sob diferentes níveis de saturação por bases em solos representativos das regiões produtoras de Minas Gerais. O experimento foi conduzido em casa-de-vegetação do Departamento de Agricultura da Universidade Federal de Lavras-UFLA. Utilizou-se o delineamento experimental de blocos casualizados em esquema fatorial ( $2 \mathrm{x}$ $4)+2$, com quatro repetições. Os tratamentos envolveram dois solos (LATOSSOLO VERMELHO AMARELO distrófico - LVAd e LATOSSOLO VERMELHO distrófico - LVd), quatro níveis de satu-
\end{abstract}

ração por bases $(40,60,80$ e $100 \%)$ mais dois tratamentos adicionais (LVAd sem calagem e LVd sem calagem). Aos 150 dias, determinaram-se o comprimento das hastes, número de folhas por haste, pesos de matéria seca de parte aérea e de raízes e relação raiz/parte aérea. Concluiu-se que, até 150 dias, o maracujazeirodoce propagado por sementes apresentou maior crescimento vegetativo quando cultivado no $\mathrm{LVd}$, em comparação ao LVAd, com ou sem calagem, e tolerou solos com baixos níveis de saturação por bases; o aumento do nível de saturação por bases no LVd reduziu o crescimento vegetativo do maracujazeiro-doce propagado por sementes, enquanto no LVAd, não influenciou o crescimento vegetativo.

TERMOS PARA INDEXAÇÃO: Saturação por bases, maracujá, Passiflora alata, latossolo.

\section{GROWTH OF SWEET PASSION FRUIT SEEDLINGS AS A FUNCTION OF LIMING}

\begin{abstract}
The objective for this work was to evaluate the growth of sweet passion fruit seedlings (Passiflora alata Dryand.) under different base saturation levels in representative soils of Minas Gerais. The experiment was carried in the greenhouse of the Agriculture Department of the Federal University of Lavras (UFLA). The statistical design used was randomized blocks in a factorial scheme $(2 \times 4)+2$, with four repetitions. The treatments involved two soil classes (Distrophic Red-Yellow Latosol - LVAd and Distrophic Red Latosol - LVd), four base saturation
\end{abstract}

levels (40, 60, 80 and 100\%) and two more additional treatments, LVAd without liming and LVd without liming. After 150 days, the stem length, number of leaves, dry matter of shoots and roots and the ratio roots/shoots were evaluated. It was concluded that the largest growth occurred in the $\mathrm{LVd}$, with or without liming. The sweet passion fruit tolerates soils with low base saturation levels. The increase of base saturation levels reduced vegetative growth of plants in the LVd but had no influence in the LVAd, until 150 days.

INDEX TERMS: Base saturation, passion fruit, Passiflora alata, latosol

1. Parte da tese apresentada pelo primeiro autor para obtenção do grau de Doutor em Agronomia - área de concentração em Fitotecnia, à UNIVERSIDADE FEDERAL DE LAVRAS/UFLA, Caixa Postal 37, 37200-000, Lavras, MG.

2. Engenheiro Agrônomo, Pesquisadora da EMPAER-MT, 78050-300, Cuiabá, MT, eldabonilha @yahoo.com.br.

3. Engenheiro Agrônomo, Professor Titular do Departamento de Agricultura da UFLA.

4. Engenheiro Agrônomo, Professora Titular do Departamento de Solos da UFLA.

5. Engenheiro Agrônomo, Professor Adjunto do Departamento de Agricultura da UFLA. 


\section{INTRODUÇÃO}

O maracujazeiro-doce (Passiflora alata Dryand.) é originário do Brasil, mas sua produção e comercialização são limitadas pela falta de hábito de consumo, pois sua fruta é ainda pouco conhecida pela população. Seu cultivo encontra-se em fase de expansão em razão das ótimas perspectivas de comercialização, principalmente por causa dos preços alcançados no mercado de fruta fresca (Braga e Junqueira, 2000). A propagação do maracujazeiro em escala comercial é feita quase que exclusivamente por sementes, podendo ser realizada também por enxertia e estaquia (Vasconcellos, 2000). Plantas propagadas por sementes possuem maior longevidade, maior desenvolvimento vegetativo e sistema radicular mais vigoroso e profundo (Fachinello et al., 1995).

Dentre os poucos estudos sobre a nutrição mineral do maracujazeiro-doce, destaca-se o trabalho desenvolvido por Cereda et al. (1991), os quais cultivaram o maracujá em vasos com areia grossa lavada por 70 dias. Os vasos foram irrigados com solução nutritiva completa e com omissão de macro e micronutrientes, o que permitiu a caracterização dos sintomas e o acompanhamento em crescimento. A carência em N determinou o menor peso de matéria seca das folhas, ao passo que plantas irrigadas com soluções sem $\mathrm{Mg}, \mathrm{Ca}$ ou $\mathrm{K}$ apresentaram maiores pesos de matéria seca das folhas, quando comparadas com plantas irrigadas com solução completa. Borges et al. (1995) avaliaram o efeito de diversas proporções de solo e esterco de curral, com ou sem calcário dolomítico, superfosfato simples e cloreto de potássio, na formação de mudas de maracujazeirosamarelo e doce. Apenas o maracujazeiro-doce respondeu à presença de adubação química, apresentando maiores altura e número de folhas, aos 104 dias. Entretanto, o peso da matéria seca das raízes do maracujazeiro-doce não foi influenciado pela adubação química.

A cultura do maracujazeiro-amarelo é considerada muito sensível à acidez e ao $\mathrm{Al}$ trocável no solo (Kliemann et al., 1986), apesar de poucos resultados de pesquisa sobre respostas à calagem. Os valores de saturação por bases recomendados para essa espécie são de 70\% (Alvarez e Ribeiro, 1999) e 80 \% (Raij et al., 1997; Silva e Oliveira, 2000). Informações acerca do comportamento do maracujazeiro-doce à acidez do solo são ainda mais escassas. A maioria dos produtores tem adotado as recomendações de calagem e adubação feitas para o maracujá-amarelo, em razão da inexistência de estudos específicos para aquela espécie (Vasconcellos, 2000).
Segundo Quaggio (2000), os valores de saturação por bases desejados dependem da tolerância à acidez ou resposta da cultura à calagem. Afora os benefícios advindos da calagem, podem ser grandes as diferenças entre plantas quanto à tolerância a solos ácidos (Jackson, 1967), o que pode resultar em diferenças em crescimento. Dessa forma, objetivou-se com este trabalho avaliar as respostas em crescimento do maracujazeiro-doce propagado por sementes, quando cultivado sob diferentes níveis de saturação de bases, em solos representativos das regiões produtoras de Minas Gerais.

\section{MATERIAL E MÉTODOS}

$\mathrm{O}$ experimento foi instalado e conduzido em casa-de-vegetação do Departamento de Agricultura da Universidade Federal de Lavras (UFLA, Lavras-MG), em vasos com capacidade de $9 \mathrm{dm}^{3}$. Cultivou-se o maracujazeiro-doce (Passiflora alata Dryand.) por 150 dias, adotando-se o delineamento experimental de blocos casualizados com quatro repetições, sendo os tratamentos dispostos em esquema fatorial $(2 \times 4)+2$, testandose duas classes de solos LATOSSOLO VERMELHO AMARELO distrófico (LVAd) e LATOSSOLO VERMELHO distrófico (LVd) e quatro níveis de saturação por bases $(40,60,80$ e $100 \%)$, mais dois tratamentos adicionais (LVAd sem calagem e LVd sem calagem).

A análise do LVAd e do LVd, segundo metodologia EMBRAPA (1998), apresentou as seguintes propriedades, respectivamente: $\mathrm{pH}$ em água $(1: 2,5)=5,2 \mathrm{e}$ 4,$2 ; \mathrm{P}=1$ e $1 \mathrm{mg} \cdot \mathrm{dm}^{-3} ; \mathrm{K}=22$ e $33 \mathrm{mg} \cdot \mathrm{dm}^{-3} ; \mathrm{Ca}=0,3$ e $0,8 \mathrm{cmol}_{\mathrm{c}} \cdot \mathrm{dm}^{-3} ; \mathrm{Mg}=0,2$ e $0,2 \mathrm{cmol}_{\mathrm{c}} \cdot \mathrm{dm}^{-3} ; \mathrm{Al}=0,1 \mathrm{e}$ $1,6 \mathrm{cmol}_{\mathrm{c}} \cdot \mathrm{dm}^{-3} ; \mathrm{H}+\mathrm{Al}=1,2$ e $4,5 \mathrm{cmol}_{\mathrm{c}} \cdot \mathrm{dm}^{-3} ; \mathrm{CTC}$ a $\mathrm{pH} 7,0=1,8$ e $5,6 \mathrm{cmol}_{\mathrm{c}} \cdot \mathrm{dm}^{-3} ; \mathrm{m}=15 \%$ e $60 \% ; \mathrm{V}=$ 32 e $19 \%$; matéria orgânica $=6$ e $23 \mathrm{~g} \cdot \mathrm{kg}^{-1}$; areia $=$ 700 e 150 g. $\mathrm{kg}^{-1}$; argila $=180$ e 750 g. $\mathrm{kg}^{-1}$.

As doses de calcário foram calculadas pelo método de saturação por bases, segundo Raij (1981). O corretivo utilizado foi uma mistura de carbonato de cálcio $\left(\mathrm{CaCO}_{3}\right)$ e carbonato de magnésio $\left(\mathrm{MgCO}_{3}\right)$, ambos puros para análise (P.A.), numa relação de 4:1. O cálculo das quantidades de $\mathrm{CaCO}_{3}$ e $\mathrm{MgCO}_{3}$ baseou-se em massa equivalente.

Após o peneiramento e pesagem, os solos foram colocados nos vasos (9 kg para o LVAd e $7,5 \mathrm{~kg}$ para o LVd). As misturas de carbonatos, correspondentes aos quatro níveis de saturação por bases testados, foram adicionadas e incorporadas de forma individual ao volume de solo de cada vaso, que permaneceram incubados com umidade correspondente a $60 \%$ do volume to- 
tal de poros por 20 dias. Os valores de $\mathrm{pH}$ real obtidos após a incubação para os solos LVAd e LVd, respectivamente, foram: 5,7 e 4,4; 5,7 e 4,6; 6,0 e 4,9; 6,1 e 5,1.

Uma semana antes da instalação dos experimentos, realizou-se uma adubação básica em todas as unidades experimentais, com as seguintes dosagens e fontes: $300 \mathrm{mg}$ de fósforo/ $\mathrm{kg}$ de solo (superfosfato simples), 0,5 mg de boro/kg de solo (ácido bórico P.A.), $1,5 \mathrm{mg}$ de cobre/kg de solo (sulfato de cobre P.A.), 3,0 $\mathrm{mg}$ de manganês/kg de solo (sulfato de manganês P.A.), $5,0 \mathrm{mg}$ de zinco/kg de solo (sulfato de zinco P.A.) e 0,1 mg de molibdênio/kg de solo (molibdato de amônio P.A.). Nitrogênio e potássio foram aplicados em cobertura (180 mg de cada nutriente/kg de solo) em quatro parcelamentos. A primeira parcela foi realizada trinta dias após a semeadura e as outras, a cada 20 dias, utilizando-se uréia e cloreto de potássio como fonte.

As sementes foram retiradas de quatro frutos selecionados, colhidos em lavoura comercial no município de Lavras-MG. Procedeu-se à semeadura direta de seis sementes por vaso, e cada bloco recebeu sementes de apenas um fruto. Após a germinação, efetuou-se o desbaste, deixando-se apenas uma planta por vaso. A parcela experimental foi constituída de quatro vasos por bloco, totalizando 160 vasos. Aos 150 dias, determinaram-se o comprimento das hastes e o número de folhas por haste. A parte aérea e as raízes foram lavadas em água corrente e em água destilada, sendo colocadas para secar em estufa com circulação de ar forçada $\left(65^{\circ}\right.$ a $70^{\circ} \mathrm{C}$ ) até atingir peso constante, e pesadas em balança de precisão. Os valores obtidos para as variáveis estudadas foram avaliados segundo Gomes (2000). As análises estatísticas foram realizadas usando o programa SISVAR, DEX/UFLA, versão 4.3 (Ferreira, 2000). Os efeitos dos tratamentos foram avaliados pelo teste $\mathrm{F}$ a $5 \%$ de probabilidade. Para a fonte de variação níveis de saturação, aplicou-se análise de regressão. O estudo da interação foi efetuado mediante a significância do teste $\mathrm{F}$, desdobrando-se níveis de saturação por bases dentro de cada classe de solo, por meio da análise de regressão. Para avaliação dos efeitos dos tratamentos adicionais, foram selecionados os seguintes contrastes: dentro de cada solo, o tratamento sem calagem versus tratamentos 40, 60, 80 e $100 \%$ de saturação por bases.

\section{RESULTADOS E DISCUSSÃO}

Houve efeito significativo da interação entre os fatores estudados, dos tratamentos adicionais e dos contrastes para comprimento de haste $(\mathrm{CH})$. $\mathrm{Pa}-$ ra número de folhas (NF), peso da matéria seca da parte aérea (PMSPA) e peso da matéria seca das raízes (PMSR), observou-se efeito significativo das classes de solo, dos tratamentos adicionais e dos contrastes. Para a relação entre peso de matéria seca de raízes e peso de matéria seca de parte aérea (R/PA), não foi observado efeito para os fatores estudados (Tabela 1).

TABELA 1 - Resumo das análises de variância para comprimento de haste $(\mathrm{CH})$, número de folhas (NF), peso da matéria seca da parte aérea (PMSPA), peso da matéria seca de raízes (PMSR) e relação entre peso da matéria seca de raízes e peso da matéria seca da parte aérea (R/PA) do maracujazeiro-doce propagado por sementes, aos 150 dias. Lavras, MG, 2002.

\begin{tabular}{lcccccc}
\hline \multicolumn{1}{c}{ FV } & GL & CH & NF & PMSPA & PMSR & R/PA \\
\hline Classes de solo & 1 & $16,84901^{*}$ & $5749,136^{*}$ & $20998,15^{*}$ & $412,6346^{*}$ & 0,004901 \\
Níveis saturação & 3 & $0,229608^{*}$ & 29,799887 & 20,995354 & 0,911986 & 0,007501 \\
Solo x níveis sat. & 3 & $0,187821^{*}$ & 12,830225 & 44,257942 & 0,287495 & 0,002040 \\
Adicionais & 1 & $1,361250^{*}$ & $1391,282^{*}$ & $3375,954^{*}$ & $57,13805^{*}$ & 0,004278 \\
Adic. vs fatorial & 1 & $0,50625^{*}$ & $55,86522^{*}$ & $74,72022^{*}$ & $5,187601^{*}$ & 0,00073 \\
Bloco & 3 & 0,020527 & $39,35014^{*}$ & 16,823763 & 7,464916 & 0,003169 \\
Erro & 27 & 0,023275 & 11,713936 & 16,111697 & 1,063908 & 0,001542 \\
\hline CV $(\%)$ & & 10,31 & 12,91 & 10,17 & 16,94 & 23,68 \\
\hline
\end{tabular}

*: Significativo a $5 \%$ de probabilidade, pelo Teste $\mathbf{F}$.

Ciênc. agrotec., Lavras. V.27, n.4, p.758-764, jul./ago., 2003 
Os valores médios do número de folhas, peso da matéria seca da parte aérea e peso da matéria seca das raízes do maracujazeiro-doce propagado por sementes e cultivado no LVd foram maiores que os obtidos no LVAd, tanto na presença como na ausência de calagem (Tabelas 2 e 3 ). A natureza física e química do solo afeta diretamente a taxa de crescimento das raízes (Rom e Carlson, 1987). Em geral, solos argilosos favorecem maior produção vegetal, em função da maior disponibilidade de nutrientes e maior retenção de umidade no solo. Além disso, por possuírem teor mais elevado de matéria orgânica, o teor de $\mathrm{N}$ desses solos é maior e pode ser protegido da ação de microrganismos mineralizadores por meio da formação de complexos organo-minerais entre o $\mathrm{N}$ e as argilas (Vale et al., 1997). De acordo com as características do $\mathrm{LVd}$, acredita-se que o maior teor de matéria orgânica e a maior capacidade de troca de cátions (CTC) apresentados possam ter possibilitado maior disponibilidade de nutrientes, resultando em maiores número de folhas e pesos de matéria seca da parte aérea e de raízes que os obtidos no LVAd.
Comparando-se os valores médios para as variáveis de crescimento do maracujazeiro-doce obtidos em função da calagem, para cada um dos solos utilizados (Tabelas 2 e 3), verificou-se que, no $\mathrm{LVd}$, as médias de todas variáveis de crescimento obtidas dos tratamentos com calagem não diferiram da média obtida nesse solo sem calagem. No LVAd, entretanto, as médias para comprimento de haste e pesos de matéria seca da parte aérea e de raízes, obtidas dos tratamentos que receberam calagem, foram menores que as médias obtidas na ausência de calagem, indicando efeito prejudicial da mesma sobre aquelas características. Dessa forma, pode-se inferir que a calagem no LVAd prejudicou o crescimento vegetativo do maracujazeiro-doce, provavelmente por causar desequilíbrio nutricional no solo. Já no LVd, não se verificou diferença significativa para as médias das variáveis de crescimento do maracujazeirodoce, quando se considera a presença ou ausência de calagem. Analisando-se o resultado deste trabalho, confirmamse os obtidos por Cereda et al. (1991) que, estudando distúrbios nutricionais em maracujazeiro-doce cultivado em solução nutritiva, verificaram maior desenvolvimento de plantas na ausência de $\mathrm{Mg}, \mathrm{Ca}$ e $\mathrm{K}$ do que em solução completa.

TABELA 2 - Valores médios ${ }^{(*)}$ do comprimento de haste $(\mathrm{CH})$ e número de folhas (NF) do maracujazeiro-doce propagado por sementes, aos 150 dias, obtidos em função das classes de solo e da calagem. Lavras, MG, 2002.

\begin{tabular}{|c|c|c|c|c|}
\hline \multirow{2}{*}{ Classe de solo } & \multicolumn{2}{|c|}{$\mathrm{CH}(\mathrm{m})$} & \multicolumn{2}{|c|}{ NF } \\
\hline & SC & $\mathrm{CC}$ & SC & $\mathrm{CC}$ \\
\hline LVAd & $1,29 \mathrm{~B} \mathrm{a}$ & $0,70 \mathrm{~B} \mathrm{~b}$ & $15,62 \mathrm{~B} \mathrm{a}$ & $12,52 \mathrm{~B} \mathrm{a}$ \\
\hline LVd & $2,12 \mathrm{~A}$ a & $2,15 \mathrm{~A}$ a & $42,00 \mathrm{~A} \mathrm{a}$ & $39,33 \mathrm{~A} \mathrm{a}$ \\
\hline
\end{tabular}

${ }^{(*)}$ Médias seguidas por letras distintas, maiúsculas nas colunas e minúsculas nas linhas, diferem entre si a $5 \%$ de probabilidade, pelo teste de $\mathrm{F}$.

$\mathrm{SC}=$ sem calagem; $\mathrm{CC}=$ com calagem

TABELA 3 - Valores médios ${ }^{(*)}$ do peso da matéria seca da parte aérea (PMSPA), peso da matéria seca de raízes (PMSR) e relação entre peso da matéria seca de raízes e peso da matéria seca da parte aérea (R/PA) do maracujazeirodoce propagado por sementes, aos 150 dias, obtidos em função das classes de solo e da calagem. Lavras, MG, 2002.

\begin{tabular}{|c|c|c|c|c|c|c|}
\hline \multirow{2}{*}{$\begin{array}{c}\text { Classe de } \\
\text { solo }\end{array}$} & \multicolumn{2}{|c|}{ PMSPA (g) } & \multicolumn{2}{|c|}{ PMSR (g) } & \multicolumn{2}{|c|}{$\mathbf{R} / \mathbf{P A}$} \\
\hline & SC & $\mathrm{CC}$ & SC & $\mathrm{CC}$ & SC & $\mathrm{CC}$ \\
\hline LVAd & $21,67 \mathrm{~B} \mathrm{a}$ & $13,18 \mathrm{~B} \mathrm{~b}$ & 4,14 B a & $2,32 \mathrm{~B} \quad \mathrm{~b}$ & 0,15 A a & 0,18 A a \\
\hline $\mathrm{LVd}$ & $62,75 \mathrm{~A} \mathrm{a}$ & $64,41 \mathrm{~A} \mathrm{a}$ & 9,48 A a & $9,50 \quad \mathrm{~A}$ a & $0,20 \quad \mathrm{~A}$ a & 0,15 A a \\
\hline
\end{tabular}

${ }^{(*)}$ Médias seguidas por letras distintas, maiúsculas nas colunas e minúsculas nas linhas, diferem entre si ao nível de $5 \%$ de probabilidade, pelo teste de $\mathrm{F}$.

$\mathrm{SC}=$ sem calagem; $\mathrm{CC}=$ com calagem

Ciênc. agrotec., Lavras. V.27, n.4, p.758-764, jul./ago., 2003 
O aumento dos níveis de saturação por bases no LVd promoveu ajuste linear decrescente para comprimentos de haste do maracujazeiro-doce propagado por sementes (Figura 1). Morales-Abanto e Muller (1977), acompanhando o crescimento do maracujazeiroamarelo até 210 dias em solução nutritiva com omissão de $\mathrm{Ca}$ ou $\mathrm{Mg}$, não verificaram sintomas visíveis de deficiência de $\mathrm{Ca}$ e $\mathrm{Mg}$ até os 120 dias. Além disso, mesmo em estado avançado de deficiência de $\mathrm{Ca}$, as plantas não apresentaram morte de gemas terminais, como normalmente ocorre com muitas espécies vegetais. Dessa forma, acredita-se que o maracujazeiro-doce possa ter baixo requerimento de $\mathrm{Ca}$ e $\mathrm{Mg}$ em sua fase inicial de crescimento. Dias et al. (1991), avaliando o efeito da aplicação de calcário na formação de mudas de taxi-branco, concluíram que essa espécie também apresentou baixo requerimento em $\mathrm{Ca}$. A calagem, além de promover a diminuição da acidez, eleva os teores de $\mathrm{Ca}$ e $\mathrm{Mg}$ nos solos. O aumento dos níveis de saturação por bases pode ter causado desequilíbrio nutricional na solução do $\mathrm{LVd}$, prejudicando a absorção de nutrientes e, conseqüentemente, o crescimento vegetal, como observado por Hylander (1995) para cevada. Segundo Marschner (1995), de maneira geral, as dicotiledôneas apresentam maior requerimento em $\mathrm{Ca}$ do que as monocotiledôneas, mas há exceções. Entre essas, o autor comenta que a espécie Lupinus angustifolius (L.) apresentou requerimento comparável ao de monocotiledôneas, seja pelo menor suprimento, seja pelo menor teor de Ca no tecido, além de ter o crescimento severamente reduzido com maiores teores de $\mathrm{Ca}$ no tecido. Esse típico comportamento calcífugo pode estar relacionado com insuficiente capacidade para comparti- mentalização e/ou inativação fisiológica do $\mathrm{Ca}$, como precipitação como oxalato de cálcio.

Neste trabalho, o maior comprimento de haste foi obtido com $40 \%$ de saturação por bases, quando o maracujazeiro-doce foi cultivado no LVd. Esse valor foi considerado baixo, diante dos sugeridos por Alvarez e Ribeiro (1999) para diversas culturas no estado de Minas Gerais, que variam de $50 \%$ a $80 \%$, exceto para eucalipto, que exige $30 \%$. Dessa forma, pode-se supor que, na fase inicial de crescimento, o maracujazeirodoce seja tolerante a solos ácidos, especialmente quando se considera o alto valor para saturação por Al do LVd. Solos tropicais são, na maioria, ácidos, e plantas de origem tropical devem ser adaptadas a essas condições.

Plantas adaptadas a solos ácidos utilizam diversos mecanismos para superar as condições químicas adversas. Esses mecanismos são regulados separadamente (como a tolerância a $\mathrm{Al}$ e $\mathrm{Mn}$ ) ou são interligados (como tolerância a Al e eficiência na aquisição de P). A tolerância a Al varia em função de espécies e cultivares (Jackson, 1967), sendo considerada o fator individual mais importante requerido para adaptação das mesmas a solos ácidos (Marschner, 1995). Os mecanismos envolvidos na diferença varietal para tolerância a Al podem ser de exclusão (imobilização de Al na parede celular, permeabilidade seletiva da membrana plasmática, barreira de $\mathrm{pH}$ induzida na rizosfera, exsudação de complexantes e/ou quelantes) ou de tolerância interna (complexação ou quelatização no citoplasma, armazenamento no vacúolo, proteínas especializadas na ligação com Al, evolução de enzimas tolerantes a Al) (Foy e Taylor, 1988, citados por Furlani, 1989).

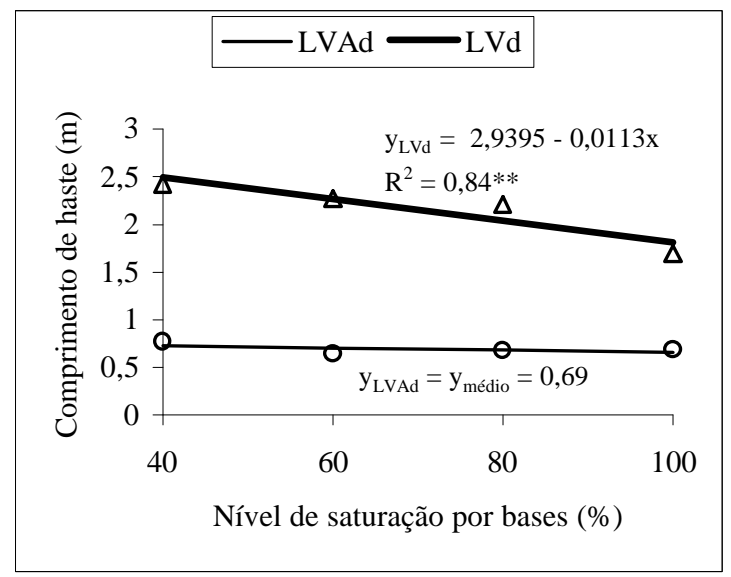

FIGURA 1 - Comprimento de haste de maracujazeiro-doce propagado por sementes, aos 150 dias. Lavras, MG, 2002. 
Pelo fato de ainda não haver recomendação de calagem específica para a cultura do maracujazeirodoce, os produtores dessa frutífera têm utilizado os valores de saturação por bases de $70 \%$ e $80 \%$, largamente utilizados para cálculo da necessidade de calagem para o maracujá-amarelo (Alvarez e Ribeiro, 1999; Raij et al., 1997; Silva e Oliveira, 2000). Entretanto, pelos resultados obtidos neste trabalho para comprimento de haste do maracujazeiro-doce cultivado em LVd e LVAd (Figura 1), acredita-se que tais valores estejam superestimados, podendo implicar em reduções em crescimento inicial, com prováveis reflexos na produção de frutos, uma vez que a fase vegetativa precede a reprodutiva. Segundo Marschner (1995), quando a produção da espécie vegetal é representada por frutos, sementes ou tubérculos, os efeitos do suprimento de nutrientes minerais sobre as curvas de respostas da produção são freqüentemente um reflexo das limitações do dreno, impostas tanto por um deficiente ou excessivo suprimento de nutrientes minerais. Esses efeitos podem ser diretos (deficiência nutricional) ou indiretos (efeitos sobre os níveis de fotossintatos ou fitohormônios).

Os valores do comprimento de haste do maracujazeiro-doce propagado por sementes e cultivado no LVAd foram inferiores aos observados no LVd, para todos os níveis de saturação por bases (Figura 1). Isso, provavelmente, se deve aos menores teores de nutrientes e capacidade de troca catiônica (CTC) daquele solo.

\section{CONCLUSÕES}

a) O maracujazeiro-doce propagado por sementes apresentou maior crescimento vegetativo quando cultivado em LATOSSOLO VERMELHO Distrófico (LVd), em comparação ao LATOSSOLO VERMELHO AMARELO Distrófico (LVAd), com ou sem calagem, até 150 dias.

b) O maracujazeiro-doce propagado por sementes tolerou solos com baixos níveis de saturação por bases, até 150 dias.

c) O aumento do nível de saturação por bases no $\mathrm{LVd}$ reduziu o crescimento vegetativo do maracujazeiro-doce propagado por sementes, até 150 dias.

d) O aumento do nível de saturação por bases no LVAd não influenciou o crescimento vegetativo do maracujazeiro-doce propagado por sementes, até 150 dias.

\section{REFERÊNCIAS BIBLIOGRÁFICAS}

ALVAREZ, V. H.; RIBEIRO, A. C. Calagem. In: COMISSÃO DE FERTILIDADE DO SOLO DO ESTADO DE MINAS GERAIS. Recomendações para uso de corretivos e fertilizantes em Minas Gerais: $5^{\text {a }}$ aproximação. Viçosa: [s.n.], 1999. p. 4360 .

BORGES, A. L.; LIMA, A. de A.; CALDAS, R. C. Adubação orgânica e química na formação de mudas de maracujazeiros. Revista Brasileira de Fruticultura, Cruz das Almas, v. 17, n. 2, p. 17-22, ago. 1995.

BRAGA, M. F.; JUNQUEIRA, N. T. V. Uso potencial de outras espécies do gênero Passiflora. Informe Agropecuário, Belo Horizonte, v. 21, n. 206, p. 72-75, set./out. 2000.

CEREDA, E.; ALMEIDA, I. M. L. de; GRASSI FILHO, H. Distúrbios nutricionais em maracujá-doce (Passiflora alata Dryand.) cultivado em solução nutritiva. Revista Brasileira de Fruticultura, Cruz das Almas, v. 13, n. 4, p. 241-244, out. 1991.

DIAS, L. E.; ALVAREZ, V. H.; JUCKSCH, I.; BARROS, N. F.; BRIENZA JÚNIOR, S. Formação de mudas de taxi-branco (Sclerolobium paniculatum Voguel). I. Resposta a calcário e fósforo. Pesquisa Agropecuária Brasileira, Brasília, v. 26, n. 1, p. 69-76, jan. 1991.

EMPRESA BRASILEIRA DE PESQUISA AGROPECUÁRIA. Centro Nacional de Pesquisa de Solos (Rio de Janeiro). Manual de análise de solo. Rio de Janeiro: EMBRAPA/CNPS, 1998. 212 p.

FACHINELLO, J. C.; HOFFMANN, A.; NACHTIGAL, J. C.; KERSTEN, E.; FORTES, G. R. de L. Propagação de plantas frutíferas de clima temperado. Pelotas: UFPEL, 1995. 179 p.

FERREIRA, D. F. SISVAR: sistema de análise de variância para dados balanceados. Lavras: DCE/UFLA, 2000. Programa de computador. 1 disquete, 31/2pol.

FURLANI, P. R. Efeitos fisiológicos do alumínio em plantas. In: SIMPÓSIO AVANÇADO DE SOLOS E NUTRIÇÃO DE PLANTAS, 2., 1989, Piracicaba. Anais... Piracicaba: ESALQ-USP, 1989. p. 73-90. 
GOMES, F. P. Curso de estatística experimental. 14. ed. Piracicaba: ESALQ-USP, 2000. 467 p.

HYLANDER, L. Changes in plant nutrition content of barley as a result of lime, phosphorus, manganese, copper and zinc supplies on trhee Swedish mineral soils in a pot experiment. Swedish Journal of Agricultural Research, Oslo, v. 25, n. 3, p. 93-107, 1995.

JACKSON, W. A. Physiological effects of soil acidity. In: PEARSON, R. W.; ADAMS, F.; DINAUER, R. C. Soil acidity and liming. Madison: American Society of Agronomy, 1967. p. 43-124.

KLIEMANN, J. H.; CAMPELO JÚNIOR, J. H.; AZEVEDO, J. A. de; GUILHERME, M. R.; GENÚ, P. J. de C. Nutrição mineral e adubação do maracujazeiro. In: HAAG, H. P. (Coord.). Nutrição mineral e adubação de fruteiras tropicais. Campinas: Fundação Cargill, 1986. p. 247-284.

MARSCHNER, H. Mineral nutrition of higher plants. London: Academic, 1995. 889 p.

MORALES-ABANTO, A.; MULLER, L. E. Alteraciones producidas en el maracuyá (Passiflora edulis Sims) por deficiencias de magnesio, calcio y azufre. Turrialba, Costa Rica, v. 27, n. 3, p. 221-225, 1977.
QUAGgIO, J. A. Acidez e calagem em solos tropicais. Campinas: IAC, 2000. 111 p.

RAIJ, B. van. Avaliação da fertilidade do solo. Piracicaba: Associação Brasileira para Pesquisa da Potassa e do Fosfato, 1981. 142 p.

RAIJ, B. van; CANTARELLA, H.; QUAGGIO, J. A.; FURLANI, A. M. C. Recomendações de adubação e calagem para o Estado de São Paulo. 2. ed. rev. e atual. Campinas: IAC, 1997. 285 p. (IACBoletim 100).

ROM, R. C.; CARLSON, R. F. Rootstocks for fruit crops. New Iork: John Wiley \& Sons, 1987. 494 p.

SILVA, J. R. da; OLIVEIRA, H. J. de. Nutrição e adubação do maracujazeiro. Informe Agropecuário, Belo Horizonte, v. 21, n. 206, p. 52-58, set./out. 2000.

VALE, F. R. do; GUILHERME, L. R.; GUEDES, G. A.; FURTINI NETO, A. E. Fertilidade do solo: dinâmica e disponibilidade dos nutrientes de plantas. Lavras: UFLA/FAEPE, 1997. $171 \mathrm{p}$.

VASCONCELLOS, M. A da S. Maracujazeiro-doce: sistema de produção. Informe Agropecuário, Belo Horizonte, v. 21, n. 206, p. 76-80, set./out. 2000. 